\title{
Cooperation and Autonomy in Language Learning: An Application of the Collage Method
}

\author{
Karen Josephine McMullin \\ Trent University
}

Received: 7 April 2015 / Accepted: 4 May 2015

ISSN: 1697-7467

\begin{abstract}
The Collage method (Möller, 2001) of language teaching uses authentic texts following an innovative process that is both specific and flexible during which students collaborate in the reading and analysis of the texts in order to build their knowledge. This study was carried out using the action-research methodology with a group of Spanish students at Trent University, Canada and consists of the adaptation and application of the Collage method to this group. The main objective of the study is to analyze the use of the method in the teaching of Spanish as a third language with a group of English-speaking students of different disciplines. The results were favourable, showing an increase in the final evaluation. Keywords: language learning, learning autonomy, communicative competence, reading comprehension, cooperation, motivation.
\end{abstract}

Cooperación y autonomía en el aprendizaje de las lenguas: una aplicación del método Collage

RESUMEN: Collage (Möller, 2001) es un método de enseñanza de las lenguas que usa textos auténticos siguiendo un proceso innovador que es específico y flexible, durante el cual el alumnado colabora en la lectura y análisis de los textos para construir conocimientos. Este estudio se realizó usando la metodología de investigación-acción con un grupo de estudiantes de español en la Universidad de Trent, Canadá y consiste en la adaptación y aplicación del método Collage a este grupo. El objetivo principal del estudio es analizar el uso del método Collage para la enseñanza de español como tercera lengua con un grupo de estudiantes angloparlantes de diversas titulaciones universitarias. Los resultados han sido favorables, mostrando un incremento en la calificación.

Palabras clave: aprendizaje de la lengua, autonomía de aprendizaje, competencia comunicativa, comprensión lectora, cooperación, motivación.

\section{INTRODUCTION}

Collage is an innovative language teaching methodology created and developed by Möller (2001), professor of German Language at the Faculty of Translation and Interpretation of the University of Granada. Its key characteristics include a textual progression using different types of authentic texts and the procedure for reading and working with these texts, implementing an authentic reading phase followed by an analytical phase. During this process, students alternate several readings of the texts with individual and group exercises using their previous knowledge in collaboration with their peers in order to discover the meaning of the texts. 
The theoretical foundations of the method include the constructivist theories, which maintain that all learning is built on previous knowledge through experience. Another important theory is that cooperative interaction promotes language learning, contributing to a relaxed atmosphere and increasing motivation (Piaget, 1972; Vygotsky, 1978; Jacobs and Hall, 2002). Working together to understand the texts provides the practice and motivation necessary to be able to deal with a variety of texts in different contexts. Also included in the theoretical bases is the theory of the influence of a positive environment in the classroom, introduced in methods like Community Language Learning, Suggestopedia and the Natural Approach, and generally accepted today. This theory holds that if a relaxed atmosphere is created in the classroom, the students feel comfortable and have confidence to practice and experiment with the language (Richards and Rogers, 2001; Krashen, 1981)

Based on these theories, Collage encourages student autonomy developed through interaction with peers in the reading and analysis of different types of texts to acquire communicative and intercultural competence through reading comprehension. Developing autonomy is essential for all students living in the present society of information and communication. It is important that they know how to reflect on the learning process, connecting previous knowledge with new concepts. According to Pinter, this formal thinking is due not so much to a natural process of maturity as to formal education (2006:9) and it is developed through practice, therefore it is advisable to familiarize students with this meta-cognitive process by providing questions about the texts and about the language and encouraging them to make comparisons with their first language. These students work together in class, comparing their answers with their peers, increasing their confidence and learning the skills necessary to tackle the texts that they will have to read and analyze independently at home, and subsequently, in life.

These characteristics, based on general guidelines, are put into practice in a flexible manner, according to the ideas of the professor, the characteristics and needs of the group and the context, in addition to the contributions of the students. This flexibility is a fundamental aspect of the implementation of the method (Möller 2001: 76/116) and what makes it possible for Collage, created originally to teach German as a second foreign language to future translators and interpreters at the University of Granada in Spain, to be adapted to the teaching of different languages in different contexts.

Language courses currently taught at university level are often based on the communicative approach with the curriculum organized around a notional-functional syllabus where the language is used to express general notions for different purposes, with emphasis on the oral expression of situational vocabulary. In this setting, language instructors are faced with the challenge of fulfilling the objective that all of their students achieve competence in oral expression of the target language, being able to express themselves correctly, with confidence and adequate pronunciation. The students, for their part, find themselves with the obligation of participating in this oral practice which does not generally take into account their different learning styles and personalities, their level of motivation, confidence and comfort with the language, or their interests.

Changing the emphasis away from oral expression to focus on reading comprehension, taking the written text as a starting point, as well as the analysis of non-graduated grammar structures, allows students to manipulate and practice the language, building a lexical and grammatical base while at the same time practicing contextualized oral expression at their 
own pace in a cooperative environment. The presentation, practice and learning of vocabulary in context is an important concept in this methodology (Möller, 2001; Moral, 2008) and students are encouraged to use the vocabulary that they have already seen and heard in the context of the texts and support materials. In this way, the assimilation of words and phrases is consolidated, facilitating retention and marking the progress of students in the learning process.

Being based on the reading of written texts, Collage helps to increase the confidence as well as the lexicon of the students, enabling them to participate actively and without fear in the oral expression of relevant and significant topics. The flexible procedure of the methodology allows for the accommodation of the different levels, learning styles and needs of the students by adjusting timing, group formation and presentation of texts. In the same way, students' interests are taken into account when choosing the texts for a particular group of learners. The flexibility of the method also allows for the inclusion of different modalities of presentation or types of texts and supporting material, taking into account recent advances in ICT and its increasing connection to education and learning. (Marín, Vazquez and McMullin, 2014). The aim of this article is to present the results of the implementation of the Collage method with a group of Spanish students at Trent University, Canada.

\section{ObJectives}

The main objective of the study is to analyze the use of the Collage method for the teaching of Spanish as a third language with a group of English-speaking students in different fields.

The specific aims of the study are:

- Address the problem of the diversity of the group in terms of the different levels of proficiency and experience with the target language, proposing the method as a possible solution to these differences by utilizing the knowledge and experience of each member of the group.

- Provide students with authentic and relevant input that motivates them to use their previous knowledge to understand the content and increase their knowledge and use of the target language.

- Promote cooperative learning because group work builds students' confidence in taking risks in the oral expression of their ideas in Spanish and in transferring their knowledge to independent work in other contexts.

\section{3. Меthod}

\subsection{Participants}

The participants in this study are students of Continuing Spanish with disparate levels and experience of the language. The majority are enrolled in their second year of study in a diverse range of degree programs, have some knowledge of French and are learning Spanish 
as a third language. The experimental group consists of fifteen students $(n=15)$, three males and twelve females between the ages of 18 and 22 years $(\mathrm{SD}=2.2)$. Four are in their first year of university having acquired a base in Spanish in high school, in a College program, or during a stay in a Spanish-speaking country. Eight are in their second year and three in third, having previously taken the Introduction to Spanish course. For the majority $(n=13)$, English is their first language and the one they speak at home, whereas for the other two, English is their second language. The majority $(\mathrm{n}=12)$ also have at least a basic knowledge of French being the second official language of Canada taught in schools from grade one, generally. Five of these twelve students have an advanced level of French, having studied their primary and secondary education in French immersion $(n=4)$ or, in one case, in a French school. The three others had not studied French. The control group consists of fifty-four students $(\mathrm{n}=54)$, thirteen males and forty-one females between the ages of 18 and 22 years $(\mathrm{SD}=2.8)$. Ten are in their first year of university, thirty-seven are in their second year and seven in third, having previously taken the Introduction to Spanish course. For the majority $(n=46)$, English is their first language and the one they speak at home, whereas for the other eight, English is their second language. The majority $(n=46)$ also have at least a basic knowledge of French and twenty-one of these forty-six students have an advanced level of French, having studied their primary and secondary education in French immersion $(n=21)$. The other eight had not studied French.

At the university the participants are enrolled in a diverse range of degree programs: business administration, environmental science, international development, anthropology, psychology, politics, forensic science, languages and literatures: French, English, Ancient Greek, and Spanish. The goals and needs of the students are also varied, prevailing among them improving their reading comprehension giving significant importance also to listening comprehension and oral expression in order to have the option to study, research or work in or with Spanish-speaking countries. Consequently, the majority study Spanish in order to be admitted to graduate studies, to increase their opportunities and possibilities in the labour market and to be qualified to work with and/or in the many different countries where Spanish is spoken in the areas of environment, anthropology, business administration, politics, psychology or to complement the study of other languages. In order to achieve these goals, the students need to be able to access written texts and also to increase their vocabulary in areas related to their future professions.

This information was obtained through a preliminary questionnaire with five dimensions: knowledge of languages, experience and attitude, learning style, areas of study and interests; and expectations. The questionnaire was distributed in class and was completed and submitted subsequently.

\subsection{Instruments}

The data were obtained following the official evaluation system for the course which consists of the following:

- Attendance and Participation: $10 \%$

- Presentations (2): $10 \%$

- Online Reading Assignments (3): 6\% 
- Written Assignments (5): 20\%

- Conversation Sessions: $15 \%$

- Multimedia Lab: $10 \%$

- Class Tests (3): $15 \%$

- Final Examination: $14 \%$

These components are included in the mid-year evaluation and in the final evaluation. For the purposes of this study, the final grade of the experimental group is compared to that of the control group. In addition, the mid-year grade and the final grade of the experimental group are compared showing an increase in the final grade of the experimental group in both comparisons thereby constituting an assessment of the effectiveness of the method.

\subsection{Design}

This transversal study is designed according to action-research methodology created 75 years ago by Kurt Lewin (Colás 1998: 291). Although there are diverse modalities, its common characteristics include participation, action-reflection and research as creation of knowledge. In all cases, the methodology proposes "la acción como respuesta a un problema" (Colás 1998: 293. According to Madrid, interpretative research, which includes action-research "es también observacional, participativa y cooperativa," (1998: 15) so that the professor has the opportunity of solving possible problems in the classroom through observation, reflection and action.

The characteristics of participation, interaction, reflection and construction of knowledge of this methodology reflect the characteristics of the teaching method that is being tested in this study. This research methodology is used in a variety of studies, including testing different teaching methods, with the professor adopting the dual role of teacher-researcher. For these reasons, this methodology was used for the current study.

\subsection{Procedure}

Before beginning their work with the texts, students are encouraged to reflect on languages and their study, career opportunities and the importance of languages for these, the level they believe they should and can reach, as well as their experiences of learning other languages. Subsequently, how and why they will be working with the texts is explained to them. It is important that they know what is expected of them and the objectives they should reach in order for them to take responsibility for their own learning process (Dickinson 1987: 80). By reflecting in this way, students become aware of their own objectives and needs and how they can achieve them, as well as some of the problems they might encounter during the process. They are given a preliminary questionnaire to sum up these questions besides determining their learning style and interests in order to adapt the selection of the texts.

When adapting the method to this group, the order in which certain elements are introduced varies, the time dedicated to certain activities, the inclusion of specific explanations or additional exercises, the omission of some steps, depending on the level of the students and the time available, or the form of presentation of the texts.

The most important adaptation of the method is the adjustment of the activities to the structure and schedule of the course. Continuing Spanish is an annual course of 96 hours 
total, divided into two hours weekly of seminar, one hour weekly of conversation and one hour weekly of language laboratory. The first semester consists of a review of the basic grammar with emphasis on oral practice. For the present study, the second part of the course was taught using the Collage method. The two weekly hours of seminar are allocated to the presentation and reading of the texts, as well as an initial analysis of them. During the conversation hour the themes of the texts and other related topics are discussed, and during the hour of language laboratory students continue with the analysis of the texts, find information on the Internet to clarify the content of the texts, or complete additional exercises. This is where complementary texts are introduced in different modalities such as videos or songs, Facebook pages or blogs to continue developing listening comprehension and provide visual aids. Classes are taught in Spanish with some explanations in English.

During the authentic reading phase, students alternate several readings of the text, depending on their complexity, with exercises to be completed individually, in pairs and in small groups. At this stage, it is important for students to read through the text once without stopping to look up unknown words, which interrupts the flow, breaking their concentration and possibly causing them to lose interest. If, however, the content of the texts is interesting to the students, they are motivated to continue reading, becoming aware that it is not necessary to look up every word they are not familiar with. (Möller, 2001; Luque Agullo, 2011) Since this group has previously acquired a basic knowledge of the language and due to the limited time for the presentation of the text, they generally read each text twice with additional readings (scanning/skimming) as needed to find specific information. Several studies have shown that language learners effectively acquire vocabulary by reading authentic texts in the target language, especially when accompanied by different types of exercises. (Pellicer-Sánchez \& Schmitt, 2010; Ma \& Sin, 2015) After the reading and exercises, the groups collaborate in the search for and construction of meaning by sharing their ideas with the class. In this way, cooperation is encouraged while increasing confidence in the peer group. According to Leslie Dickinson "The major sources of inhibition for most language learners are the group of other learners within the class and sometimes the teacher. Inhibition increases as the feeling of competitiveness increases and decreases with the development of co-operation within the group." (1987: 26) With the Collage method all the members of the class collaborate toward a common goal with the help and guidance of the professor who constantly encourages and motivates them, creating a relaxed and safe environment of collaboration and cooperation. In this way, inhibition is kept to a minimum and the participation of all is facilitated, in the class work as well as in the learning process.

In the same way, after reading the texts several times, their content and related topics are discussed in pairs or small groups in the conversation class before presenting ideas informally to the class. This process facilitates the transfer of ideas, and thereby of competence in reading comprehension to oral expression. During this component of the course, students bring to the group different perspectives of the material based on their interests, experience, area of study and other knowledge.

The analytical reading phase consists of focusing on the forms of the language, including grammar structures, lexicon and characteristics of the texts. The observation and understanding of these different aspects of the language is a useful and necessary part of language learning. (Möller, 2001; Allford and Pachler, 2007; McMullin, 2013). During this phase, the students create their own personal annotations where they record the different elements of the texts 
and language, organizing and classifying them in categories in order to more readily access this information for future use and learning. In this way, the work with the texts as well as the learning process is personalized, since individual students record the elements that they consider most important and useful and organize them in categories of their choice.

During this process, the students learn not only to take responsibility and control of their learning and to reflect on the language and on the texts, but to manage and select this information, to investigate sources and to know when and how to use them together with the different types of dictionaries and other reference works. The cultural topics that they explore through the content of the texts are themes of interest to this group. They also become aware, through the analysis of the texts, that the language, apart from transmitting culture through content, represents the culture in the form of expression of this content and that by reading and analyzing the texts, they are gaining access through them to the increasingly multicultural world.

In this sense, another important adaptation is in the type of texts selected for this group. The students read complex authentic texts of different types and themes in order to improve their knowledge of the target language and culture of the countries where it is spoken as well as of topics of interest. Their interest in the content paired with their successful general comprehension of the texts motivates them to continue working with the texts, transforming language learning into an attainable goal rather than an insurmountable obstacle.

The texts are selected based on the areas of study of the students, taking into account also their interests and experience. The texts are divided into two themes, which correspond to two lessons: Ambiente and Gente. Each lesson consists of four texts with questions to do in class and four texts with questions to do at home. The types of texts used include articles, biographies, songs, stories and official websites, all addressing different topics related to the environment or to the lives and work of Spanish-speaking people. After each lesson, some of the main grammar structures were reviewed with practice exercises.

Collage focuses on the development of reading comprehension, forming a firm base on which to build knowledge and competence in the other skills. With this group, oral comprehension and expression are also practiced as well as written expression based on the needs and interests of the students and on the objectives of the course, always starting from the reading and analysis of written texts. The majority of these students study Spanish in order to be admitted to graduate studies, to improve their opportunities and possibilities in the labour market and to be qualified to work with and in Spanish-speaking countries. For this, they need to be able to access written texts and also to increase their vocabulary in areas related to their future professions.

According to Resnick, during the reading process readers use a combination of what is written, what they already know and processes such as making inferences, finding connections, checking and organizing to build a representation of the message they think the author is trying to convey (cited in Hirsch 1995: 13). During this process, they learn to think about the content, meaning and structure of the texts by practicing reading in the language, at the same time increasing their lexicon and establishing a base for oral practice. With Collage, this same analytical and strategic approach is applied to the reading of texts in a second or third language.

Being based on the reading of written texts, Collage helps to build vocabulary as well as the confidence of the students, enabling them to participate actively and without fear in 
the oral expression of the language. Increasing the focus on reading comprehension helps to accommodate the different learning styles and needs of the students. Although most students tend to be hesitant to express themselves orally in another language, their main goal is be able to speak the language, therefore, students are encouraged to participate in conversations about the texts and related topics, using the target language throughout the course. Pronunciation is also practised from the beginning, and at the end of the semester students do an oral presentation on one of the topics covered in the texts and in class. Students are also required to write short compositions related to the themes of the texts. However, these aspects of the course are carried out always starting from the reading and analysis of the written texts.

\section{RESULTS}

Before proceeding with the data analysis, a test of normality was performed to verify the normality hypothesis, thereby ensuring the reliability of the analyses. The Shapiro-Wilk test was used due to the small size of the sample $(n=15)$. The results of this test indicate that the sample is coherent for both groups, control and experimental, respectively (Sig. 0.086 y 0.142 ).

After verifying the normality of the distribution, the statistical analyses were carried out. The first analysis is descriptive and indicates that the mean of the final grade is higher in the experimental group ( $M=83.00)$, with a lower standard deviation ( $D S=11.06)$, which shows a positive relationship between the application of the program (Collage method) and the final evaluation. Next, a statistical analysis was performed to compare the means using the $\mathrm{T}$ test for independent samples. The results of Levene's test for equality of variances indicates that the assumption of equal variances was met, showing equal variances across the two groups $(\mathrm{F}=0.17, \mathrm{p}=0.898)$. The results of the $\mathrm{T}$ test show that there is a significant difference in the group means (Sig.-2-tailed=.013), indicating that participants taught using the Collage method of language teaching achieved higher grades at the end of the program $(\mathrm{M}=83.00, \mathrm{SE}=2.855, t(67)=-2.538, \mathrm{p}=0.013, \mathrm{r}=0.3)$ compared to the participants of the control group $(\mathrm{M}=74.13, \mathrm{SE}=1.66)$. The results of these analyses are shown in table 1 below.

Table 1. Group Statistics

\begin{tabular}{|l|l|l|l|c|c|}
\hline & Group & $\mathrm{N}$ & Mean & Std. Deviation & Std. Error Mean \\
\hline \multirow{2}{*}{ FGrade } & Control & 54 & 74.13 & 12.204 & 1.661 \\
\cline { 2 - 6 } & Experimental & 15 & 83.00 & 11.058 & 2.855 \\
\hline
\end{tabular}

Below, the results of the evaluation of the participants $(\mathrm{N}=69)$ are displayed by means of two radial diagrams (Graphs 1 and 2). In the first diagram it can be seen clearly that the final grade of the control group decreases with respect to the mid-year grade, whereas the experimental group increases the final grade with respect to the mid-year grade. In the second diagram, the mid-year grade is superimposed over the final grade in such a way that it can be clearly observed that the experimental group stands out by exceeding the limits of the MG when the Collage method is used, while the FG of the control group only surpasses the $\mathrm{MG}$ in certain spots. 


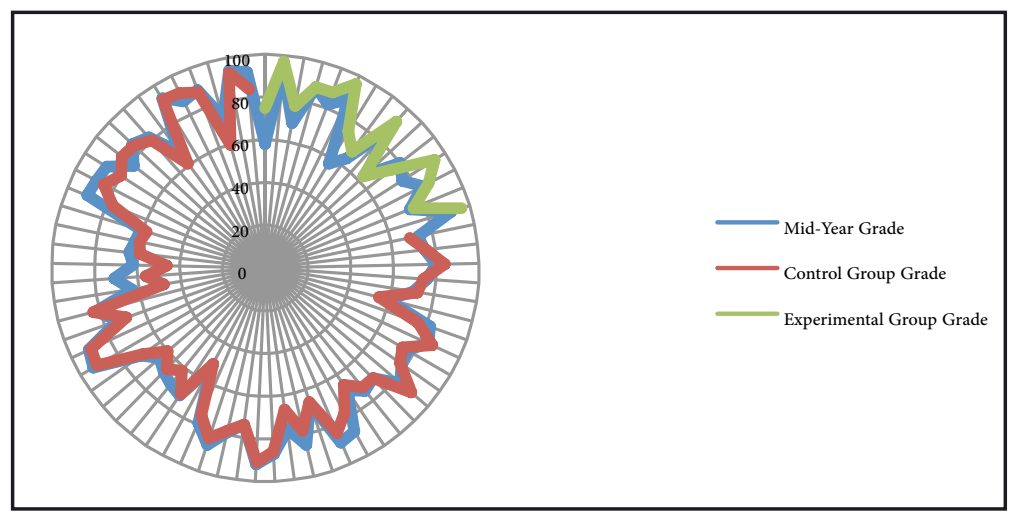

Graph 1

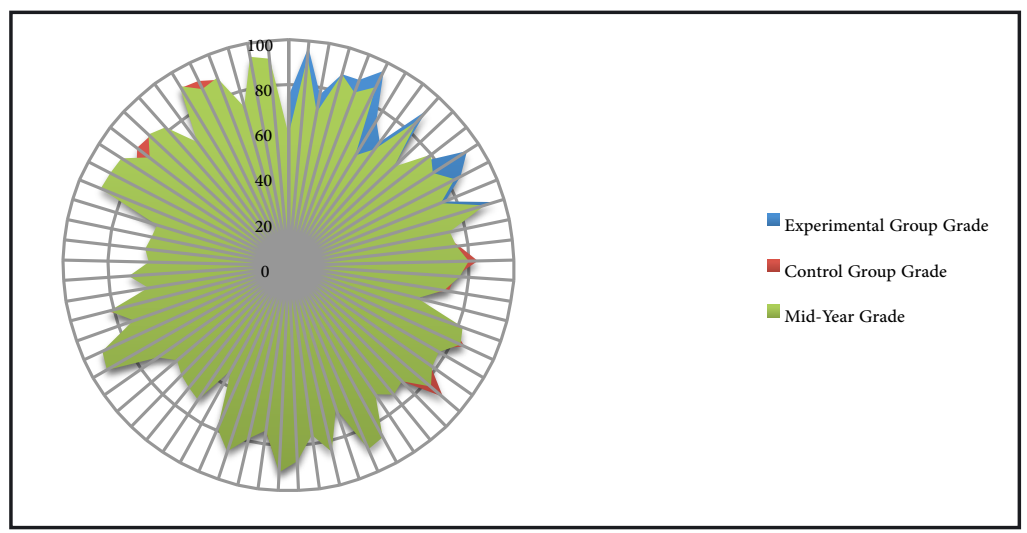

Graph 2

\section{Discussion AND CONCLUSION}

After carrying out the statistical analyses and based on the results obtained from these, it can be seen that the application of the program had a positive influence on the academic achievement of the students. Given the cumulative nature of language learning, based on the assimilation of previous knowledge, when languages are taught using the graduated presentation of vocabulary and grammar structures of more traditional methods, the tendency is for the academic achievement of the students to decrease over the course of the academic year, resulting in the final grade being lower than the mid-year grade. The current study confirms this tendency in the control group in contrast to the experimental group to which the Collage method was applied. Although the size of the experimental group is small, the 
results confirm that there was a significant increase in the final evaluation compared to the mid-year grade of the same group as well as compared to the final grade of the control group. These results indicate that the use of the Collage method is effective for teaching Spanish as a third language to a group of English-speaking students pursuing a variety of degrees.

The study confirms that after practicing the reading comprehension and analysis of complex texts in a cooperative environment, students increased their vocabulary and their confidence, facilitating their active participation in the oral expression of relevant and significant topics, motivated by their interest in the themes of the texts. The flexibility of the procedure allows students to learn at their own pace, going into more or less depth, depending on their previous knowledge, while they are all encouraged to learn as much as they can from each text.

It is evident from the study that the Collage method effectively addresses the problem of the diversity of this group in terms of the different levels of proficiency and experience with the target language, allowing students to work at their own pace, to form work groups and contribute to the group depending on their knowledge, experience and interests. Because it is based on a textual progression using different types of texts students are provided with authentic and relevant input based on their studies and interests, which motivates them to use their previous knowledge to understand the content and increase their knowledge and use of the target language.

Because of the small size of the sample for the experimental group, it is necessary to continue to apply the method to this and other groups of similar characteristics in order to confirm that it continues to be effective in the ways mentioned above. It would also be interesting to explore its use with other groups in different contexts, including graduate studies and continuing education.

\section{REFERENCES}

Allford, D. and Pachler, N. (2007). Language, Autonomy and the New Learning Environments. Bern, Switzerland: Peter Lang AG, International Academic Publishers.

Colás, M.P. (1998). "La investigación-acción", in M.P. Colás and L. Buendía (eds.), Investigación educativa. Sevilla: Alfar, 291-315.

Dickenson, L. (1987). Self-instruction in Language Learning. Cambridge: Cambridge University Press.

Hirsch, B. (1995). Languages of Thought. New York: College Entrance Examination Board.

Jacobs, G. and Hall, S. (2002). "Implementing Cooperative Learning", in J.C. Richards and W.A. Renandya (eds.), Methodology in Language Teaching. An Anthology of Current Practice. New York: Cambridge University Press.

Krashen, S. (1981). Second Language Acquisition and Second Language Learning. Oxford: Pergamon Press.

Luque Agullo, G. (2011). "Cómo explotar textos para trabajar la lectura en el aula de lengua extranjera (inglés). Ejercicios para fomentar la creatividad e imaginación", in Porta Linguarum, 15: 233-245.

Madrid, D. (1998). Guía para la investigación en el aula de idiomas. Granada: Grupo Editorial Universitario. 
Marín Díaz, V., Vázquez Martínez, A.I., and McMullin, K.J. (2014). "First Steps towards a University Social Network on Personal Learning Environments", in The International Review of Research in Open and Distance Learning, IRRODL, 15(3): 93-119.

Ma, Q. and Sin, C.H. (2015). "Teaching Young Learners English Vocabulary with Reading-Based Exercises in a Real Classroom Situation", in Porta Linguarum, 23: 125-138.

McMullin, K. (2013). "Collage: Una metodología de enseñanza de una tercera lengua", RedELE, 25: $1-25$

Möller, J. (2001). Siglo XXI: ¿Innovamos? La enseñanza de una segunda lengua extranjera. España: Editorial Alhulia, S.L.

Moral Barrigüete, C. (2008). "La enseñanza-aprendizaje del vocabulario en ELE con el método Collage". PUBLICACIONES, 38: 183-193.

Pellicer-Sánchez, A. \& Schmitt, N. (2010). "Incidental vocabulary acquisition from an authentic novel: do things fall apart?", in Reading in a Foreign Language, 22: 31-55.

Piaget, J. (1972). The psychology of the child. New York: Basic Books.

Pinter, A. (2006). Teaching Young Language Learners. Oxford: Oxford University Press.

Richards, J.C. and Rodgers, T.S. (2001). Approaches and Methods in Language Teaching. Cambridge: Cambridge University Press.

Vygotsky, L. S. (1978). Mind in Society: The Development of Higher Psychological Processes. Cambridge, Massachusetts: Harvard University Press. 